\title{
The Good and the Bad. An Evaluation of Project-based Learning with Peer Assessment in a Large Class Context
}

\author{
Margit Kastner \\ WU Vienna University of Economics and Business \\ margit.kastner@wu.ac.at
}

\begin{abstract}
To overcome the negative consequences associated with large class sizes and to support students in developing the necessary competences (e.g., critical thinking, problem-solving) a marketing course has been redesigned by implementing, as a voluntary course part, project-based learning with peer assessment (PBL\&PA). This study aims to evaluate students' perception towards PBL\&PA using an onlinequestionnaire and students' learning achievement using final grades. Among the 260 students who filled out the questionnaire, $47 \%$ participated in $P B L \& P A$. Although students' participation was initially extrinsically motivated, students mainly experienced learning and social benefits. Parts of the technical implementation, however, were judged negatively and team aspects generated mixed feelings. Examining students' grades at the final exam uncovered that students who did not participate in any of the offered active learning tasks performed poorest while students who used all activities (clicker and PBL\&PA) were best. In conclusion, goals of the implementation were met and usage is recommended.
\end{abstract}

\section{Introduction}

In these days, the relationship between students and faculty is a problem at many universities [2] which affects teaching and assessment methods. Large class sizes with conventional lecture delivery and multiplechoice exams become a common part of the setup at universities in particular at undergraduate level. However, such a setup is perceived impersonal [24] and disengaging [7] and it does not fit well with universities' goals of improving the quality of students' learning experience and of supporting students to develop the necessary competences such as critical thinking, problem-solving, communication, and team-work skills that enable them to take up positions in modern companies. Instead, the predominantly applied assessment method is the multiple-choice exam which fosters recall, rewards memorization, and encourages guessing which is consistent with surface learning rather than deep learning [17].

Taking into account the scarce resources, the previously mentioned negative consequences of todays' teaching and assessment methods, and universities' goals, a marketing course was redesigned in two steps. First, the lecture was enriched with multi-media applications such as videos, current ads, and to foster active learning clicker questions. This step took place a few semesters ago and had the power to enhance students' interaction, engagement, and attention as well as the ability to improve students' knowledge and grades [25] which is in line with previous research [e.g., 26, 27, 41]. Second, recently project-based learning including peer-assessment (PBL\&PA) became part of the course. This means that students explore a realworld problem, find a solution, and evaluate the results of peers while working in small collaborative groups. Problem-based learning is generally accepted to promote deeper learning, improve students' ability to work in teams, and enable them to acquire critical thinking skills $[30,39]$. It furthermore helps to stimulate students' interest and enthusiasm for the subject [30].

To this end, it is essential to gain a deeper insight into the redesign from the students' and lecturer's point of view. Thus, the study aims to answer the following research questions: (1) What triggered students (non-) participation in PBL\&PA? (2) What benefits and challenges students encounter completing the PBL\&PA assignment? (3) Does PBL\&PA have a positive impact on students' academic performance and the interest for the subject? (4) Is it worthwhile to use PBL\&PA in large classes?

The paper's main contribution is to show that PBL\&PA can be used in a large class environment with limited resources most universities have to consider and that students value PBL\&PA. Moreover, the reader will receive many hints on purely practical procedures and advices on what one must be bear in mind when using PBL\&PA.

To accomplish the author's objectives, the paper 
continues with a few remarks on the theoretical background, followed by a thorough description of the implementation of PBL\&PA. Then, a presentation of the methodology and the findings follow. The paper ends with a discussion and concluding remarks.

\section{Review of relevant literature}

Educators face the challenge of using learning strategies that involve students in the classroom to make their learning more effective. Chickering and Gamson [9] offer an important guidance to faculty who would like to enhance students' learning by concluding that good practice in education, among others, encourages students-faculty contact and cooperative learning among students, fosters students' involvement in class activities, increases "time on task" for students (active learning), and attaches importance to providing prompt feedback. In the following, PBL\&PA are discussed in more detail, which implement these "good practice in education" very well.

\subsection{Project-based learning}

Project-based learning (PBL) is not a modern invention. Already more than 100 years ago, educators have shared the benefits of experimental, hands-on learning [13] and in 1918, the early pioneer of projectlearning Kilpatrick suggested such instructions should include four steps (i.e., purposing, planning, executing, and judging) [33]. Today, PBL is defined as an active learning method in which students work in collaborative groups to solve a real-world problem [21]. However, such problems never have a single correct answer. Thus, students learn to analyze the problem, to use appropriate information sources, to share their ideas, and finally, to develop new, authentic solutions largely independently. While doing so, students gain equally knowledge of theories and concepts [32] as well as management skills such as time and project management or goal-setting [13]. Moreover, there is evidence that PBL improves students argumentation skills [22] and academic achievement [18].

In general, aims for the integration of PBL in courses are manifold, ranging from mastery the subject matter to the application of knowledge, the promotion of critical thinking [20,30], and the improvement of communication skills [20] and teamwork competences $[30,39]$. It is also deployed to arouse students' interest and stir up their enthusiasm for the subject [30]. Related to these goals is the question whether these goals are met or not. Articles that measure the impact of PBL are, however, scarce [20]. Many anecdotal references provide evidence of the positive effect of PBL on students with regard to engagement [40], interest, enjoyment, or satisfaction [20]. A longitudinal study over a period of three years compared the performance of students in two different schools, one with a conventional curricular and one with a PBL curricular [5]. Although students of both schools acquired the rote knowledge of concepts, students with the PBL curricular were better off because they developed more flexible forms of knowledge. This means that they were able to better transfer their knowledge to other problems. Thus, they scored significantly better at the national examination compared to the students with the conventional curricular. Other scholars [e.g., 22, 23] confirm that and add that students also utilize more effective self-directed learning strategies. However, Colliver's review [11] comparing PBL with traditional education shows no conclusive proof for the effectiveness of PBL.

Despite of all its benefits there is also the other side of the coin. Problems and challenges that most frequently occur in practice are connected to the timeconsuming organisation and administration of such PBL courses, students' motivation and workload, and poor group dynamics [20].

Technology, however, has the potential to tackle several of these problems [4] and can support both, students and lecturers.

\subsection{Peer assessment}

Peer assessment (PA) is a method wherein students judge the quality of the work of peers [37], usually anonymously [1]. It is furthermore a reciprocal process, which means that students not only provide but also receive feedback. A growing body of literature highlights the benefits of PA and its value for the learning process [16] whereas giving feedback seem to be more effective than receiving it [10]. Judging others requires critical thinking and higher order cognitive skills, such as argumentation and reasoning. This enables students to reflect on their own work and improve it $[19,31]$. The increased interaction with the content also promotes students' engagement [3], motivation [12], and subsequently, satisfaction with the course [35].

Despite of all these benefits, the fear of some lecturers regarding the reliability and validity of peer assessment may prevent PA usage. However, research has shown that the majority of peers provide useful feedback; only the feedback of $7 \%$ [36] to $11 \%$ [8] is poor. Moreover, it is possible to increase the quality of judgements by providing an assessment scheme that makes clear prescriptions on the use of the scales as well as by a small number of categories [37]. 


\section{Research setting}

The next chapter provides first background information on the study context. Then, it explains the implementation of PBL\&PA in detail before focusing on the measures for the evaluation and the analyses.

\subsection{Marketing course}

Briefly, the objective of the marketing course is to provide a basic grounding in the theory and practice of marketing featuring a blended learning approach, wherein the face-to-face course is enhanced by thoughtfully combining it with online components. With regard to the face-to-face instructions, all courses have the same setting: It is a voluntary offer, has the same female lecturer, starts on Wednesday at 8:00 a.m. and lasts for three hours, and is hold in a classroom equipped with fixed seats in auditorium-style for up to 650 students.

The lecture has undergone a process of renewal a few semesters ago by integrating multi-media applications such as videos, current ads, and clicker questions. An evaluation showed that students perceive clicker questions as useful and enjoyable [25]. Furthermore, the embedment resulted in enhanced engagement and attention as well as in an improvement of students' knowledge and grades.

Students' knowledge is assessed applying a multiple-choice exam. This means that students are accustomed to finding solutions to problems or questions that are supported by different answer alternatives. In the further course of their study and in professional life, however, students need to apply their knowledge actively. Unfortunately, we are observing in consecutive marketing courses that this kind of knowledge utilization is extremely difficult for the students because they are not used to it. Thus, it is important to train it and to sharpen their skills for critical analytical thinking as early as possible. For this reason, a further step in the redesign of the marketing course was put into practice and PBL\&PA became an optional part of the course.

\subsection{Implementation of PBL\&PA}

To begin with, the course lecturer examined the possibilities of implementing this new application in depth because resources are scarce. As said, one lecturer conducts this course and the university does not provide additional personnel for the implementation of PBL\&PA. Thus, the regular future application needs to be feasible without causing an excessive additional workload. However, the e-learning team of the university offered a technical solution that facilitates the various stages of the PBL\&PA.

Breaking down the PBL\&PA cycle into steps (see Figure 1) allows the lecturer to design, implement, and assess PBL\&PA. Step 1 is the most important step. It involves preparatory work at which the lecturer needs to decide the topic of the PBL project, which learning goals should be achieved, how it will be implemented into the curriculum, how support for students can be arranged, and how it can be embedded into the e-learning platform. For the marketing course the application of one strategic instrument, the SWOT analysis, was selected to be the appropriate PBL\&PA assignment, for several reasons. First, it is a powerful support for decision-making. Second, this instrument is commonly used by businesses and organizations and universally applicable. Third, students will fulfill the same task but for different companies on the market. Thus, it prevents the often practiced "copy paste" behavior of students and allows in the same way that students are able to evaluate the work of peers. Step 2, the establishment of the registration, is only necessary when - like in the case of the course the study is based on - PBL\&PA is a voluntary task. After setting up the registration offered by the e-learning platform, students are informed using the message board of the e-learning platform and traditional announcement during the lecture that they have to register for the PBL\&PA. Since participation is voluntary, this results in registrations of interested students only. Step 3 is to assign all registered students to teams. In their meta-analysis, Helle et al. [20] conclude that PBL groups consisting of three to five students are feasible for most purposes. For this reason, all groups of the marketing course have four members. Then, the lecturer spreads the contact information of all team-members via e-mail; due to privacy issues, students do not have access to that information using the PBL assignment tool at our e-learning platform. When the groups are assigned it is also possible to publish the PBL\&PA tasks on the e-learning platform (Step 4). Each team is told that their team is employed as company consultants for a real-life company (which is the team's name) for which they have to create a SWOT analysis and derive strategic options that arise for the company. After submitting their work, each team has to evaluate the work (SWOT analysis including strategies) of three competing consultants (student teams). To assure that these peer assessments are reliable and valid, the lecturer needs to provide assessment criteria, which is Step 5. Furthermore, some assignment prototypes (one good, one medium, and one bad) have to be developed, which can later be used as a benchmark for automatic grading. All students also have to evaluate the work of the peers within their team individually to prevent free riding by distributing $100 \%$ among all team 
members $(25 \%$ for each student would mean that all students contributed equally to the PBL\&PA assignment). Unfortunately, the e-learning platform does not support it, so that a tool for online surveys is used. As a final step (Step 6), the lecturer has to grade the assignments and provide feedback. For grading, the e-learning system applies automatic grading using the algorithm by Loll \& Pinkwart (2009). This algorithm takes a teams' own work and their peer assessment into account. In doing so, the score of the accuracy of the peer assessment, called base value $(b)$, is given by

$$
b=1-\frac{1}{c} \sum_{i=1}^{c} \frac{\left(\left|w_{i}-q_{i}\right|\right)}{\max \left(q_{i}, 1-q_{i}\right)}
$$

where $c$ is the number of given peer assessments, $w$ is the score of the peer assessment one gives, and $q$ is the quality value of the groups for whom the peer assessment is given (see below). The evaluation value (e), the weighted score of a groups own solution, is specified by

$$
e=\frac{1}{\sum_{i=1}^{j} q_{i}}\left(\sum_{i=1}^{j} w_{i} q_{i}\right)
$$

where $w$ is the score of the peer assessment one receives, and $q$ is the quality value of the groups from whom one receives the peer assessment. Finally, the scores of the evaluation value $(e)$ and the base value $(b)$ are combined into the quality value $(q)$ using the equation

$$
q=\frac{c}{p+c} b+\frac{p}{p+c} e
$$

where $c$ is the number of given peer assessments, and $p$ the number of received peer assessments.

Lastly, some adjustments to account for free riding are made.

Figure 1: Steps of the PBL\&PA cycle

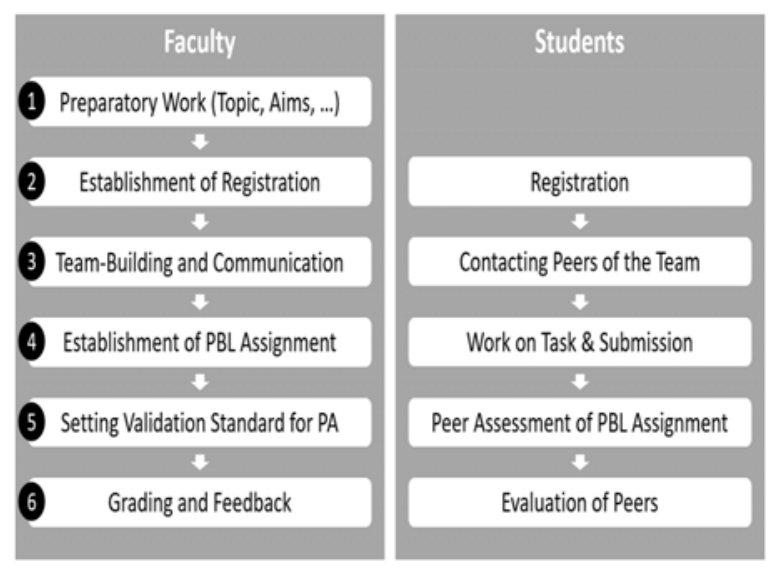

\subsection{Measures}

In order to answer the research questions, a mixed methods approach was chosen for this study. In doing so, the study comprises student's final grade (measured on a 100-point scale) without consideration of bonus points, data collected from students by means of an online questionnaire, and the views of the lecturer of the underlying course. The questionnaire, containing a mix of close-ended questions and open-ended questions, was devised to investigate students' motivations, benefits, and problems they encounter when completing the PBL\&PA assignment, and their subject valuation. Open-ended questions were newly designed but closedended items were taken from Sprague \& Dahl [38], the ETL Project [15], and Pintrich et al. [34]. In order to be able to combine questionnaire data with students' grades and scores, the questionnaire also comprised a question obtaining students' permission, which students had to approve by entering their registration number. Using a "forward-backward" translation procedure [6], all items were translated into German. The questionnaire required only minor adjustments in wording after the pretest with 20 participants.

\subsection{Analyses}

The aim of the qualitative analysis is to identify structures in the answers of the open-ended questions. Applying the qualitative content analysis as proposed by Mayring [29], categories were developed inductively. To ensure scientific quality, a multi-level coding process was used, involving several coders. [28]. In the first stage, one coder was going through the material and deducted step-by-step categories which were tentative. Within a feedback loop (stage 2), another coder revised the codes and categorization by reviewing the original data. In case the second analyst coded some aspects differently, the first and the second coder had to agree upon a coding in a team meeting. This stage also resulted in a reduction to main categories. In the third stage, another reevaluation involving a third researcher took place. Finally, all researchers compared their coding and discussed discrepancies until they reached consensus.

For analyzing quantitative data, frequency, variance, and correlation analyses as well as $\chi^{2}$ goodness-of-fit are performed.

\section{Results}

This chapter covers the composition of the sample and results of the study to answer the research questions. 


\subsection{Sample description}

In total, around 700 students signed up for the course. However, as neither attendance nor participation is obligatory, only about 200 students were present during the lecture and out of them around 150 students decided to join the optional PBL\&PA. 423 students took the exam after the course and 260 students filled out the questionnaire. Among the 260 participants, $47 \%$ worked on the PBL\&PA. Participants were on average 21.82 years old (SD 2.74) and almost evenly distributed between female $(52 \%)$ and male $(48 \%)$ students. To control for representativeness, $\chi^{2}$ goodness-of-fit tests were run. They provide evidence that the sample's gender distribution does indeed match that of the students at the university ( $\chi^{2}$ goodness-of-fit test for female students: $\chi^{2}=.010, p=.922$; for male students: $\left.\chi^{2}=.010, p=.919\right)$.

\subsection{Reasons for (not) participating}

In total, students provided 204 individual reasons for participating and 175 for not participating in PBL\&PA, which could be condensed into a few categories.

Most important for students' participation were extrinsic benefits (106 comments) in form of bonus credits, which they usually mentioned first. However, learning (49 comments) and social benefits (43 comments) also played an important role. For instance, students were motivated by the expectation that they would better understand the subject, apply theoretical concepts, and get to know other students. A few comments (6) were related to the interest in the topic.

Comments of students who did not participate in PBL\&PA had predominately to do with students' organization and management (123 comments). This means that they did not know about it, that they missed the registration deadline, or that they had time constraints because they e.g., took another course that were at the same time. Some students (30 comments) also had concerns with regard to teamwork. They feared, for instance, unmotivated or unknown team members, difficult communication with team members, or they have had negative previous teamwork experiences. 19 comments were connected to disutility (i.e., high workload, additional work, and low bonus credits), two comments to lack of interest, and one student commented on the missing clarity of the assignment description.

\subsection{Benefits and challenges students encounter}

In total, students provided 332 statements on their experience with the PBL\&PA. Most importantly, students mentioned more positive than negative aspects.

As shown in Table 1, students commented on many different aspects. Two thirds of them refer to perceived intrinsic benefits. Among them are learning and social benefits. In particular, they appreciate that they can apply their knowledge and perceive an enhancement of understanding. Very important are also social benefits. PBL\&PA allows them to work in groups and find new social contacts. Some comments refer to the PBL\&PA itself and its implementation in the course.

Table 1. Benefits and positive aspects of PBL\&PA

\begin{tabular}{|c|c|c|}
\hline Categories & $\#$ & Comments \\
\hline $\begin{array}{l}\text { Learning } \\
\text { benefits }\end{array}$ & 69 & $\begin{array}{l}\text { Application of theory (24), better understanding } \\
\text { of the topic (17), comparison with others (11), } \\
\text { feedback on own work ( } 7 \text { ), gain in learning } \\
\text { through peer review (3), active learning and } \\
\text { working (2), learn something new (2), enlivens } \\
\text { the lecture (2), critical thinking (1) }\end{array}$ \\
\hline $\begin{array}{l}\text { Extrinsic } \\
\text { benefits }\end{array}$ & 4 & Bonus credits (4) \\
\hline Subject value & 15 & Insights into industries (15) \\
\hline Social benefits & 58 & $\begin{array}{l}\text { Working collaboratively (23), new social contacts } \\
\text { (19), interaction with other students (13), shared } \\
\text { experience and mutual support (2), study group } \\
\text { (1) }\end{array}$ \\
\hline Team aspects & 17 & $\begin{array}{l}\text { Group harmony ( } 7) \text {, engagement and motivation } \\
\text { of team members (5), punctuality of team } \\
\text { members (1), competence of team members ( } 1) \text {, } \\
\text { workload (1), balanced division of duties ( } 3) \text {, } \\
\text { transparent division of duties (1) }\end{array}$ \\
\hline $\begin{array}{l}\text { Organizational } \\
\text { aspects / setup } \\
\text { of assignment }\end{array}$ & 5 & $\begin{array}{l}\text { Group allocation (2), time distance to the exam } \\
\text { (1), group size (1), fair assessment (1) }\end{array}$ \\
\hline $\begin{array}{l}\text { Technical } \\
\text { setup }\end{array}$ & 2 & Ease with regards to the registration (2) \\
\hline $\begin{array}{l}\text { Assignment } \\
\text { aspects }\end{array}$ & 20 & $\begin{array}{l}\text { Topic of the assignment (9), level of detail and } \\
\text { clarity of assignment description (4), design } \\
\text { flexibility and independent working (3), peer- } \\
\text { evaluation of team-members (2), professional } \\
\text { work with bibliography (1), transparency and } \\
\text { comprehensiveness of the evaluation scheme (1) }\end{array}$ \\
\hline
\end{tabular}

The comments with regard to learning benefits are also confirmed by the closed-ended learning benefit items used. Nearly all students (95.9\%) appreciate that they could actively apply their knowledge. The real-life example helped $84.6 \%$ of the respondents to develop a deeper understanding of the learning matter and 78.0\% feel more confident in the subject matter after the assignment. Moreover, 69.1\% uncovered by assessing other students' work which amendments they would have to make in their own work.

However, students' remarks on the system and its implementation in the course are rather critical (see Table 2). Especially the technical setup stands out. In 
particular, students most often perceived problems were with respect to the upload format of the assignment. Moreover, students found that the description of the assignment lacked clarity and details. Negative comments occurred also in connection to the workload.

Comparing positive and negative aspects concerning team aspects one can see that students had different experiences. While some students gained positive experiences, others encountered negative ones and they criticize team members' engagement and motivation.

Table 2. Challenges and negative aspects of PBL\&PA

\begin{tabular}{|c|c|c|}
\hline Categories & $\#$ & Comments \\
\hline Team aspects & 31 & $\begin{array}{l}\text { Engagement and motivation of team members } \\
\text { (18), team communication and organization (11), } \\
\text { competence of team members (1), team meetings } \\
\text { (1) }\end{array}$ \\
\hline $\begin{array}{l}\text { Organizational } \\
\text { aspects / setup } \\
\text { of assignment }\end{array}$ & 13 & $\begin{array}{l}\text { Group allocation (6), long term assessment (1), } \\
\text { short deadline (4), offered support (2) }\end{array}$ \\
\hline $\begin{array}{l}\text { Technical } \\
\text { setup }\end{array}$ & 36 & $\begin{array}{l}\text { Format of the upload of the assignment (35), one } \\
\text { deadline for two tasks (1) }\end{array}$ \\
\hline $\begin{array}{l}\text { Assignment } \\
\text { aspects }\end{array}$ & 39 & $\begin{array}{l}\text { Level of detail and clarity of assignment } \\
\text { description (19), selection of companies (3), } \\
\text { transparency and comprehensiveness of the } \\
\text { evaluation sheet (4), level of feedback (3), topic } \\
\text { of the assignment (2), difficulty level of the tasks } \\
\text { (5) }\end{array}$ \\
\hline Workload & 31 & $\begin{array}{l}\text { Relation of bonus credits to workload (18), } \\
\text { workload (3) }\end{array}$ \\
\hline
\end{tabular}

\subsection{Impact on students' academic performance and on subject value}

Examining how students perform at the exam is imperative for understanding the impact of this innovative approach to classroom education. The comparison of the three groups, (1) students who did not take part in any of the voluntary offers, (2) students who answered clicker questions during the lecture, and (3) students who took an active part in PBL\&PA, is shown in Table 3.

Table 3. Students' academic performance

\begin{tabular}{lrrrr}
\hline Grades & $\begin{array}{c}\text { Points } \\
\text { achieved }\end{array}$ & \multicolumn{2}{c}{ Students who participated in } \\
no tasks & clicker & $\begin{array}{c}\text { clicker and } \\
\text { PBL\&PA }\end{array}$ \\
& & $(\mathbf{n}=\mathbf{2 5 7 )}$ & $\mathbf{( n = 7 8 )}$ & $\mathbf{( n = 8 8 )}$ \\
\hline Unsatisfactory & $0-60$ & $30.0 \%$ & $24.3 \%$ & $18.7 \%$ \\
Adequate & $61-70$ & $16.3 \%$ & $14.1 \%$ & $19.8 \%$ \\
Satisfactory & $71-80$ & $32.1 \%$ & $34.6 \%$ & $30.8 \%$ \\
Good & $81-90$ & $19.6 \%$ & $20.5 \%$ & $25.3 \%$ \\
Very Good & $91-100$ & $2.1 \%$ & $6.4 \%$ & $5.5 \%$ \\
\hline
\end{tabular}

One can see that results are best for students who participated in all voluntary learning task (Anova: $F(2)=3.940 ; p=.020$ ). Interestingly, not a single student participated in the PBL\&PA task only. All of them also answered clicker questions.

In addition, $69.9 \%$ of the respondents who participated in PBL\&PA reported that the project had a boost on their interest in and enthusiasm for the subject.

\subsection{Lecturers' evaluation}

The lecturer of the course was, in general, satisfied with the collaboration with the developers of the supporting technical solution and the implementation of PBL\&PA.

According to the lecturer who also assessed all assignments for this study, the teams' assessment scores are valid and reliable and peer-evaluations were found to be essential because many teams had free riders.

However, there is also room for improvements. First, a connection between the registration for the PBL\&PA assignment and the group assignment tool would help to facilitate team compilation. Second, the lecturer would appreciate automatic e-mails that provide teams with the necessary contact information of team members. Third, the lecturer had to deal with several students claiming that the editor of the assignment upload is poor. Fourth, there is only one deadline for the whole PBL\&PA assignment. Since students had time management problems, it would be better to have separate deadlines for the first task (PBL) and the second task (PA). It is expected that this will lead to even better PA scores. Fifth, the allocation of the PBL assignments is not evenly distributed so that there are several assignments without PA. This means that the lecturer must grade these PBL assignments. Sixth, the adjustment to account for free riding must also be done manually and an automatic procedure would facilitate the lecturers' work.

\section{Discussion and conclusion}

This chapter contains a discussion of major findings as related to literature, implications for lecturers and the developers of supporting information technology, future research possibilities, and limitations of the study. Finally, it concludes with a clear "take-home message".

\subsection{Discussion of major findings and implications for lecturers and developers of the supporting information technology}

To summarize what one can learn from this study each research question is reiterated and discussed in the 
following.

What triggered students (non-)participation in PBL\&PA? Although students are predominately motivated to participate by extrinsic benefits (i.e., bonus credits), they also see that they can benefit in terms of learning and new social contacts which is in line with implementation goals pursued by the literature $[16,20,30,32,39]$ as well as the goals of the course. Students who did not participate seem to have problems with the organisation and management of their studies because they - although registered for the course - were not informed about PBL\&PA, missed the registration deadline for the PBL\&PA assignment, or had time constraints. However, if PBL\&PA is used on a longterm basis, then some of these aspects are expected to disappear because students usually discuss such issues in the students' Facebook forums or WhatsApp groups. Other students had concerns with regard to poor group dynamics, which corroborates earlier findings [20]. Another problem stated earlier by Helle et al. [20], students' lack of motivation, also came up in this study because students highlight that the workload is too high and that they would not receive enough bonus credits.

(2) What benefits and challenges students encounter completing the PBL\&PA assignment? Interestingly, the predominantly reported extrinsic motivation is hardly mentioned when students were asked about benefits. Thus, it seems that - in accordance with the General Interest Theory [14] - offering rewards for performance deem to be important because of its symbolic value, which signals that students' competence is valued and that the task is important which subsequently, enhances students' intrinsic motivation. After performing the task, students mentioned a multitude of learning and social benefits. Among them are issues already mentioned in literature such as better understanding of the subject matter, application of knowledge, the promotion of critical thinking [20, 30], working collaboratively enhancing teamwork competences [30, 39], and feedback on and reflection of the own work due to peer assessment $[19,31]$. In addition, they value this active learning method, which enlivens the lecture and allows insights into the industry. More precisely, students learn more about four different local companies, which differ for instance in terms of size, degree of internationalization, corporate form, and products produced. Students also see a benefit in getting to know other students with whom they even study e.g., for the exam. This is essential since a survey by the university at hand revealed that students in the first phase of their studies struggle with social distance due to the lecture-style teaching format and large class-sizes [42]. Social distance is also identified as one driver of the high dropout rates the university has to deal with. Moreover, students benefit of mutual support. This means they make fewer mistakes, help each other, can fix their own problems, redistribute tasks to do the work effectively and efficiently, and are more resilient. On the other hand several students have to cope with lacking engagement and motivation of team members which is one of the challenges also mentioned in literature [20]. They also highlight difficulties with regard to their team communication and organization. Since the teacher does the grouping and students do not know each other in advance, some of these communication problems arise already at the very beginning. This is because some students do not check their study mail address; however, the lecturer sends contact information of the peers to this address. An intelligent solution within the e-learning platform (e.g., communication directly via the elearning system, pop-up showing a new message, button for group message, etc.) could solve this problem. At the same time, it would also facilitate a lecturer's work. Another idea is to let teams select their own members within the lecture. It might also be possible that students' are discouraged by the company assigned. Thus, more freedom which company a team has to work on might help. The lecturer's evaluation reveals another issue with regard to students' time management. As described, the technical solution only gives one deadline for the whole PBL\&PA assignment, which results in late submissions of the actual PBL assignment. Thus, students have to assess other students' work under time pressure. For this reason, two separate deadlines for the first task (PBL) and the second task (PA) could enhance students' assessment and help them with their time management.

Most urgent are improvements concerning the assignment upload and the level of detail and clarity of the assignment description because they received most comments. It is further recommended to explain the task within the lecture in more detail, to perform a group exercise where they have to identify good parts and mistakes within a finished assignment (SWOT analysis including derived strategies), and to provide a best practice example students can study before starting the assignment.

Lecturers also need to address students' concerns about the high workload, a problem that is mentioned within this and prior studies [20]. It is recommended that lecturers inform students, that the ETCS of the course equals 150 hours of work and how this is distributed to the different tasks of the course.

(3) Does PBL\&PA have a positive impact on students' academic performance and the interest for the subject? This study is in support of studies where PBL outperformed conventional instruction [e.g., 5, 22, 23]. However, in the study at hand all students who completed PBL\&PA also participated in another active learning activity (i.e., clicker questions) what limits 
findings. In addition, students' academic performance was measured using a multiple-choice exam. However, this type of exam does not require the type of learning trained through PBL\&PA and it would be interesting to see the effect of it applying other exam types to test students' knowledge, ability of critical thinking and reasoning, or communication skills.

Consistent with previous findings [30], this study shows that PBL\&PA helps to arouse students' interest for the subject. This is achieved by the topic selected which was found to be appealing by the students and, in particular, by using real-life examples for which students had so complete a task commonly used in the industry. Since students' increase in interest is only measured ex-post by self-reports of students, a longitudinal future study could better inform about the enhancement of the value ascribed to the subject before and after completing the PBL\&PA assignment. This would also control for the self-selection bias because it might be possible that only students with a higher subject value register for the PBL\&PA assignment and this, consequently, might have an impact on students' achievement in the final exam and therefore, explain inconsistencies concerning its impact on grades.

(4) Is it worthwhile to use PBL\&PA in large classes? In light of the gathered data in the study, the given benefits and the positive impact on students' final grades and interest are in support of implementing PBL\&PA. It is also a feasible move to use it in large classes when technical support - as described in this study - is available and when suggested improvements are implemented. Lecturers do not have to fear and can trust in students' assessment scores, which enable automatic grading, which consequently, keeps a lecturer's workload within limits when used on a regular basis. Most time-consuming is the first set-up of the PBL\&PA assignment.

To conclude with, application is encouraged.

\subsection{Limitations and areas for future research}

Yet, several limitations in this study should be addressed.

As already mentioned, students' performance is only measured by means of a multiple-choice test although PBL\&PA empowers them to utilize higher-cognitive learning skill. Thus, applying another form of exam could reveal if these learning goals are met. Further research could also examine long-term effects of PBL\&PA, e.g., in the further course of their study (consecutive marketing courses) or after they graduate looking at real-world projects.

Although there are limits to what can be generalized from a single case, most results are not domain-specific and thus, applicable to PBL\&PA in other domains.
Results are also in accordance with literature. Nonetheless, further studies should be undertaken and explore the potential value of PBL\&PA across the different disciplines.

Comparative research with regard to automatic grading is also highly appreciated.

Finally, this research should be repeated after amendments of the supporting technical solution in order to see their impact.

\subsection{Main take-away and conclusion}

PBL \& PA can foster academic excellence and better prepare our future leaders so that they can meet expectations set upon them. Therefore, and because it should be the goal of lectures to help prepare their students, it is hoped that lecturers at other universities will use PBL\&PA described here to reinvent their classrooms in a way that enables students to develop higher-order cognitive skills, collaboration skills, organisational skills, and communication skills which means that they engage in meaningful learning.

\section{References}

[1] Barak, M. and S. Rafaeli, "On-line question-posing and peerassessment as means for web-based knowledge sharing in learning," International Journal of Human-Computer Studies, vol. 61 , no. 1,2004 , pp. 84-103.

[2] Bates, A.W.T., Managing technological change. San Francisco: Jossey-Bass, 2003.

[3] Bloxham, S. and A. West, "Understanding the rules of the game: marking peer assessment as a medium for developing students' conceptions of assessment," Assessment Evaluation in Higher Education, vol. 29, no. 6, 2004, pp. 721-733.

[4] Blumenfeld, P.C., E. Soloway, R.W. Marx, J.S. Krajcik, M. Guzdial, and A. Palincsar, "Motivating project-based learning: Sustaining the doing, supporting the learning," Educational psychologist, vol. 26, no. 3-4, 1991, pp. 369-398.

[5] Boaler, J., Experiencing School Mathematics: Teaching Styles, Sex, and Setting. Buckingham, UK: Open University Press, 1997.

[6] Bradley, C., "Translation of questionnaires for use in different languages and cultures," in Handbook of Psychology and Diabetes: a guide to psychological measurement in diabetes research and practice, Hove - New York: Psychology Press, 1994, pp. 43-55.

[7] Buck, H.J., "Maximizing student learning with the use of random oral questioning in the college classroom," Florida Journal of Educational Research, vol. 37, no. 1, Available: http://www.coedu.usf.edu/fjer/1997/1997_Buck.htm 
[8] Caulk, N., "Comparing teacher and student responses to written work," Tesol Quarterly, vol. 28, no. 1, 1994, pp. 181-188.

[9] Chickering, A.W. and Z.F. Gamson, "Seven principles for good practice in undergraduate education," AAHE Bulletin, vol. 3, 1987, pp. 3-7.

[10] Cho, Y.H. and K. Cho, "Peer reviewers learn from giving comments," Instructional Science, vol. 39, no. 5, 2011, pp. 629643.

[11] Colliver, J.A., "Effectiveness of problem-based learning curricula: research and theory," Academic medicine, vol. 75, no. 3, 2000, pp. 259-266.

[12] Deeley, S.J. and C. Bovill, "Staff student partnership in assessment: enhancing assessment literacy through democratic practices," Assessment Evaluation in Higher Education, vol. 42, no. 3, 2017, pp. 463-477.

[13] Denholm, J. and L. Lee-Davies, Enhancing Education and Training Initiatives Through Serious Games (2017). Hershey PA: IGI Global, 2017.

[14] Eisenberger, R., W.D. Pierce, and J. Cameron, "Effects of reward on intrinsic motivation-Negative, neutral, and positive: Comment on Deci, Koestner, and Ryan (1999)," Psychological bulletin, vol. 125, no. 6, 1999, pp. 677-691.

[15] ETL Project. (2002, 13.6.2019). ETL Experiences of Teaching and Learning Questionnaire (ETLQ). Available: http://www.etl.tla.ed.ac.uk/questionnaires/ETLQ.pdf

[16] Falchikov, N. and J. Goldfinch, "Student peer assessment in higher education: A meta-analysis comparing peer and teacher marks," Review of educational research, vol. 70, no. 3, 2000, pp. 287-322.

[17] Furnham, A., A. Christopher, J. Garwood, and N.G. Martin, "Ability, demography, learning style, and personality trait correlates of student preference for assessment method," Educational Psychology, vol. 28, no. 1, 2008, pp. 15-27.

[18] Gültekin, M., "The Effect of Project Based Learning on Learning Outcomes in the 5th Grade Social Studies Course in Primary Education," Educational Sciences: Theory \& Practice, vol. 5, no. 2, 2005, pp. 548-556.

[19] Harland, T., N. Wald, and H. Randhawa, "Student peer review: enhancing formative feedback with a rebuttal," Assessment Evaluation in Higher Education, vol. 42, no. 5, 2017, pp. 801-811.

[20] Helle, L., P. Tynjälä, and E. Olkinuora, "Project-based learning in post-secondary education-theory, practice and rubber sling shots," Higher Education, vol. 51, no. 2, 2006, pp. 287-314.

[21] Hmelo-Silver, C.E., "Problem-based learning: What and how do students learn?," Educational psychology review, vol. 16, no. 3, 2004, pp. 235-266.
[22] Hmelo, C.E., "Problem-based learning: Effects on the early acquisition of cognitive skill in medicine," Journal of the Learning Sciences, vol. 7, 1998, pp. 173-208.

[23] Hmelo, C.E. and X. Lin, "Becoming self-directed learners: Strategy development in problem-based learning," in Problembased learning: A research perspective on learning interactions, D. Evensen and C. E. Hmelo, Eds., Mahwah, NJ: Erlbaum, 2000, pp. 227-250.

[24] Hoekstra, A., "Vibrant student voices: Exploring effects of the use of clickers in large college courses," Learning, Media and Technology, vol. 33, no. 4, 2008, pp. 329-341.

[25] Kastner, M., "The Use of an Audience Response System to Monitor Students' Knowledge Level in Real-Time, Its Impact on Grades, and Students' Experiences," in 49th Hawaii International Conference on System Sciences (HICSS), 2016, pp. 104-113: IEEE.

[26] Kay, R.H. and A. LeSage, "Examining the benefits and challenges of using audience response systems: A review of the literature," Computers \& Education, vol. 53, no. 3, 11// 2009, pp. 819-827.

[27] Lymn, J.S. and A. Mostyn, "Audience response technology: Engaging and empowering non-medical prescribing students in pharmacology learning," BMC Medical Education, vol. 10, no. 73, 2010, pp. 1-10.

[28] MacQueen, K.M. and G. Guest, Handbook for Team-Based Qualitative Research. Plymouth, UK: Altamira Press, 2008.

[29] Mayring, P., Qualitative Inhaltsanalyse - Grundlagen und Techniken, 11th ed. Weinheim/Basel: Beltz, 2010.

[30] Neo, M. and T.-K. Neo, "Engaging students in multimediamediated Constructivist learning-Students' perceptions," Journal of Educational Technology \& Society, vol. 12, no. 2, 2009, pp. 254-266.

[31] Nicol, D., A. Thomson, and C. Breslin, "Rethinking feedback practices in higher education: a peer review perspective," Assessment Evaluation in Higher Education, vol. 39, no. 1, 2014, pp. 102-122.

[32] Palincsar, A.S. and L.R. Herrenkohl, "Designing collaborative contexts: Lessons from three research programs," in Cognitive Perspectives on Peer Learning, A. M. O'Donnell and A. King, Eds., Mahwan, NJ: Erlbaum, 1999, pp. 151-178.

[33] Pecore, J.L., "From Kilpatrick’s project method to projectbased learning," in International Handbook Of Progressive Education, Pensacola, FL: University of West Florida, 2015, pp. 155-171.

[34] Pintrich, P.R., D.A.F. Smith, T. Garcia, and W.J. McKeachie, "Reliability and predictive validity of the Motivated Strategies for Learning Questionnaire (MSLQ)," Educational and Psychological Measurement, vol. 53, no. 3, 1993, pp. 801-813. 
[35] Richardson, J. and K. Swan, "Examing social presence in online courses in relation to students' perceived learning and satisfaction," Journal of Asynchronous Learning Networks, vol. 7, no. 1,2003 ,

[36] Rollinson, P., "Peer response and revision in an ESL writing group: a case study," Ph. D. thesis, Universidad Autonoma do Madrid, 1998.

[37] Sadler, P.M. and E. Good, "The impact of self-and peergrading on student learning," Educational assessment, vol. 11, no. 1, 2006, pp. 1-31.

[38] Sprague, E.W. and D.W. Dahl, "Learning to Click. An Evaluation of the Personal Response System Clicker Technology in Introductory Marketing Courses," Journal of Marketing Education, vol. 32, no. 1, 2010, pp. 93-103.

[39] Thomas, J.W., A review of research on project-based learning. San Rafael, CA: Autodesk Foundation, 2000.

[40] Torp, L. and S. Sage, Problem as possibilities: Problembased learning for K-16 education. Alexandria, VA: Association for Supervision and Curriculum Development, 2002.

[41] Voelkel, S. and D. Bennett, "New uses for a familiar technology: introducing mobile phone polling in large classes," Innovations in Education and Teaching International, vol. 51, no. 1, 2014, pp. 46-58.

[42] WU, Evaluierung der Studieneingangsphase. Unpublished. . Vienna: Vienna University of Economics and Business, 2017. 